\title{
Prevalence, pathogenesis and management of prediabetes and type 2 diabetes mellitus in patients with polycystic ovary syndrome
}

\author{
Sofia Lazaridou, ${ }^{1}$ Konstantinos Dinas, ${ }^{2}$ Konstantinos Tziomalos ${ }^{1}$
}

${ }^{1}$ First Propedeutic Department of Internal Medicine, Medical School, Aristotle University of Thessaloniki, AHEPA Hospital, Thessaloniki, Greece; ${ }^{2}$ Second Department of Obstetrics and Gynecology, Medical School, Aristotle University of Thessaloniki, Hippokration Hospital, Thessaloniki, Greece

\begin{abstract}
Polycystic ovary syndrome (PCOS) is the most common endocrinopathy in women of reproductive age. PCOS is not only the leading cause of anovulatory infertility but is also associated with an array of metabolic disorders, among which impaired glucose metabolism has been a topic of intense research. The aim of the present narrative review is to summarize the findings of the studies that have evaluated the prevalence and incidence of prediabetes and type 2 diabetes mellitus (T2DM) in patients with PCOS, to analyze the factors underpinning the association between T2DM and PCOS and to discuss the current strategies for screening and management of impaired glucose metabolism in this population. Both prediabetes and T2DM are highly prevalent in patients with PCOS. Accordingly, regular screening is recommended in this population for the early identification of impaired glucose metabolism, particularly in overweight or obese patients and in those with a family history of T2DM. Prevention of T2DM in patients with prediabetes is primarily based on lifestyle changes, while metformin might be considered in selected cases. The treatment of T2DM is similar in patients with and without PCOS but appropriate contraceptive measures should be implemented in patients receiving treatments other than insulin, metformin or glyburide.
\end{abstract}

Key words: Impaired glucose tolerance, Insulin resistance, Obesity, Polycystic ovary syndrome, Type 2 diabetes mellitus

Address for correspondence:

Konstantinos Tziomalos, MD, PhD, First Propedeutic

Department of Internal Medicine, AHEPA Hospital,

1 Stilponos Kyriakidi Str., 54636 Thessaloniki, Greece;

Tel.: +30-2310-994621, Fax: +30-2310-994773,

E-mail: ktziomalos@yahoo.com

Received: 01-10-2017, Accepted: 18-12-2017

\section{INTRODUCTION}

Polycystic ovary syndrome (PCOS) is the most common endocrinopathy in women of reproductive age. ${ }^{1,2}$ PCOS is mainly characterized by oligo- or anovulation, clinical and/or biochemical hyperandrogenism and polycystic ovaries and is the leading cause of anovulatory infertility. ${ }^{3,4}$ However, PCOS is also 
associated with an array of metabolic disorders, among which impaired glucose metabolism has been a topic of intense research. Indeed, several cross-sectional and some prospective studies reported increased prevalence and incidence of impaired glucose tolerance (IGT) and type 2 diabetes mellitus (T2DM) in these patients. ${ }^{5}$

The aim of the present narrative review is to summarize the findings of the studies that evaluated the prevalence and incidence of prediabetes and T2DM in patients with PCOS, to discuss the factors underpinning the association between T2DM and PCOS and to present the current recommendations for screening for and management of impaired glucose metabolism in this population. A narrative review was chosen instead of a systematic review or a meta-analysis because the heterogeneity of the studies included in the review is too large, rendering the systematic review and the meta-analysis impossible to perform.

\section{METHODS}

We searched the PubMed for relevant articles using the following keywords: polycystic ovary syndrome, impaired fasting glucose, impaired glucose tolerance, type 2 diabetes mellitus, prediabetes, insulin resistance, diet, exercise, pharmacotherapy. References of retrieved articles were also evaluated for the identification of additional pertinent papers.

\section{PREVALENCE OF PREDIABETES AND T2DM IN PATIENTS WITH PCOS}

In an early case-control study in 254 patients with PCOS and 80 age- and weight-matched controls, the prevalence of IGT was 2.7 times higher in the former (31.1 vs. $14.0 \%$, respectively). ${ }^{6}$ Moreover, $7.5 \%$ of patients with PCOS had T2DM compared with none in the women in the control group. ${ }^{6}$ In a more recent large study in 11,035 patients with PCOS, the prevalence of T2DM was 2.45 times higher than in agematched controls. ${ }^{7}$ In a meta-analysis of 13 studies that compared the prevalence of IGT between patients with PCOS and controls, IGT was 2.48 times more frequent in the former. ${ }^{5}$ Likewise, the prevalence of T2DM was 4.5 times higher in patients with PCOS than in controls in a meta-analysis of 15 studies $^{5}$ and, importantly, these differences were similar in studies that included body mass index (BMI)-matched populations. ${ }^{5}$ Of note, it has been estimated that $15.0-35.6 \%$ of all incident cases of T2DM in white women are attributable to PCOS. ${ }^{8}$ Metabolic syndrome, which is associated with increased risk for T2DM, ${ }^{9}$ is also more frequent in patients with PCOS, ${ }^{10,11}$ while, in contrast, the prevalence of impaired fasting glucose or of $\mathrm{HbA}_{1 \mathrm{c}}$ levels in the prediabetic range (i.e. between 5.7 and $6.4 \%$ ) appears to be low in patients with PCOS. ${ }^{12,13}$

\section{INCIDENCE OF PREDIABETES AND T2DM IN PATIENTS WITH PCOS}

There are very limited data on the incidence of prediabetes and T2DM in patients with PCOS. In an early uncontrolled study in 67 patients with PCOS, $9 \%$ and $8 \%$ of patients with normal glucose tolerance developed IGT and T2DM, respectively, during a follow-up period of 6.2 years. ${ }^{14}$ Moreover, 54\% of patients who had IGT at baseline developed T2DM. ${ }^{14}$ In a more recent study in 95 patients with PCOS and age- and BMI-matched controls, the incidence of T2DM during an 8-year follow-up period was 2.3 times higher in the former $(13.4 \%$ and $5.8 \%$, respectively). ${ }^{15}$ Moreover, obese patients with PCOS had a fivefold greater risk of developing T2DM than controls..$^{15}$ In another study, the incidence of IGT was 2.4 higher in patients with PCOS than in controls, albeit this difference did not reach significance due to the small sample size ( $\mathrm{n}=35$ and 23 , respectively). ${ }^{16}$ In a more recent uncontrolled study in 255 patients with PCOS followed up for 16.9 years, the incidence of T2DM was 1.05 per 100 person-years and the age-standardized prevalence of T2DM at the end of follow-up was significantly higher than that of the general female population of a similar age (39.3 and $5.8 \%$, respectively). ${ }^{17}$ In another recent retrospective analysis of a large longitudinal database, patients with PCOS $(n=21,740)$ had a 3 times higher risk of developing T2DM during a follow-up of 4.7 years. ${ }^{18}$ Interestingly, the incidence of T2DM was also 1.7 times higher in patients with PCOS than in BMImatched controls. ${ }^{18}$ 


\section{PATHOGENESIS OF PREDIABETES AND T2DM IN PCOS}

Insulin resistance (IR) is intimately involved in the increased risk for prediabetes and T2DM in PCOS, ${ }^{14}$ with IR being present in approximately $60-80 \%$ of patients with PCOS and in $95 \%$ of obese patients with this syndrome. ${ }^{19,20}$ In addition, IR worsens with age in patients with PCOS..$^{21,22}$ The pathogenesis of IR in patients with PCOS is multifactorial. ${ }^{23}$ Insulinstimulated glucose uptake is mediated by the activation of phosphatidylinositol-3 kinase, while insulin-induced cell growth and differentiation is mediated through the mitogen-activated protein kinase (MAPK) http:// www.sciencedirect.com/topics/biochemistry-geneticsand-molecular-biology/mapk-erk-pathway/ extracellular signal-regulated kinase (ERK) that stimulates a cascade of enzymes, including serine/threonine, Raf, MAPK and MAPK-ERK $1 / 2 .{ }^{24}$ A pivotal study in obese and non-obese patients with PCOS showed that IR in this syndrome is independent of obesity and is due to impaired insulin action..$^{23}$ More recent studies also support the presence of an intrinsic IR in patients with PCOS. ${ }^{25,26}$ Higher basal insulin secretory rates and attenuated secretory responses to meals have also been reported in patients with PCOS, which factors contribute to hyperinsulinemia in this population. ${ }^{27-29}$ In contrast, insulin clearance does not appear to be reduced in patients with PCOS. ${ }^{23}$

Obesity characterizes $40-70 \%$ of patients with PCOS and is another key contributor to the pathogenesis of impaired glucose metabolism in this population. ${ }^{11,30,31}$ In a case-control study in 254 patients with PCOS and 80 age- and weight-matched controls, both BMI and waist/hip ratio (WHR) were independent predictors of IGT, ${ }^{6}$ while other studies have also reported higher BMI and WHR in patients with PCOS and IGT than in those with normal glucose tolerance. ${ }^{32,33}$ In prospective studies, obesity was also independently associated with increased incidence of IGT or T2DM in patients with PCOS. ${ }^{14}$ Obesity appears to exert a synergistic, independent, adverse effect on glucose metabolism, this accompanied by the added burden of intrinsic IR that characterizes patients with PCOS. ${ }^{23}$ Body composition, including increased ratio of truncal/lower body fat and higher inter- and intramuscular adipose tissue also contribute to the aggravation of IR in this population..$^{34,35}$
Hyperandrogenism might also play a role in the pathogenesis of prediabetes in patients with PCOS. Indeed, patients with PCOS and hyperandrogenemia have more pronounced IR than patients without hyperandrogenemia. ${ }^{36-38}$ It has further been shown that treatment with androgens impairs insulin sensitivity, whereas antiandrogens improve insulin sensitivity, ${ }^{39-41}$ while in addition it appears that IR aggravates obesity in patients with PCOS. ${ }^{42,43}$ Moreover, several studies reported that free testosterone levels are higher in patients with PCOS and IGT than in those with normal glucose metabolism. ${ }^{33}$

Impaired glucose metabolism in patients with PCOS additionally appears to have a strong genetic background, since a positive family history of T2DM increases the risk for IR and prediabetes in this population. ${ }^{44}$ Moreover, women with monozygotic twin sisters with PCOS have twice the risk of developing the syndrome. ${ }^{45}$ In a number of studies, polymorphisms in several genes, including thyroid associated protein, DENN/MADD domain containing $1 \mathrm{~A}$ and luteinising hormone/choriogonadotropin receptor, were associated with increased risk for PCOS. ${ }^{44-48}$ Developmental programming, i.e. changes in gene expression due to the presence of increased steroids, mostly androgens, during fetal development, also appears to increase the risk for IR, prediabetes and T2DM in offspring of patients with PCOS. ${ }^{49}$

Emerging data suggest that the gut microbiome might also be implicated in the pathogenesis of impaired glucose metabolism in patients with PCOS..$^{50}$ In a recent pilot study, specific taxa of gut bacteria were associated with lower serum androgen levels and lower prevalence of oligo-amenorrhea. ${ }^{51}$

Muscle mitochondrial dysfunction has also been recently reported in patients with PCOS and might also play a role in the development of T2DM in this population. ${ }^{52}$

\section{SCREENING FOR PREDIABETES AND T2DM IN PATIENTS WITH PCOS}

According to the recent guidelines of the American Association of Clinical Endocrinologists, the American College of Endocrinology and the Androgen Excess and PCOS Society, an oral glucose 
tolerance test (OGTT) should be performed every 1 to 2 years in patients with PCOS based on a family history of T2DM and a BMI $>30 \mathrm{~kg} / \mathrm{m}^{2}$, while this test should be performed every year in patients with PCOS and IGT. ${ }^{53}$ A recent position statement of the PCOS Special Interest Group of the European Society of Endocrinology recommends performing an OGTT in all obese patients with PCOS as well as in lean middle-aged patients ( $>40$ years), in the presence of a personal history of gestational diabetes or family history of T2DM. ${ }^{54}$ In contrast, both Societies mention than measurement of fasting glucose levels and $\mathrm{HbA}_{1 \mathrm{c}}$ appears to have limited sensitivity in identifying prediabetes in patients with PCOS. ${ }^{12,13,55}$ The Endocrine Society recommends performing an OGTT in all patients with PCOS every 3-5 years or more frequently if central adiposity, substantial weight gain or symptoms of T2DM develop. ${ }^{53}$ In patients unable or unwilling to perform an OGTT, measuring $\mathrm{HbA}_{1 \mathrm{c}}$ might be considered. ${ }^{56}$ Moreover, the European Society of Endocrinology mentions that measurement of serum insulin and estimates of insulin resistance are not required for routine clinical management. ${ }^{54}$

\section{MANAGEMENT OF PREDIABETES AND T2DM IN PATIENTS WITH PCOS}

Lifestyle changes, including diet, exercise and behavior modification, represent first-line treatment for all overweight and obese patients with PCOS..$^{53,56,57}$ A hypocaloric diet (500-1000 kcal/d reduction) with reduced intake of saturated fats and increased intake of mono- and polyunsaturated fats, fiber, whole-grain breads, cereals, fruits and vegetables is recommended, along with at least $30 \mathrm{~min}$ of moderate-intensity physical activity daily ${ }^{56,57}$ A reduced carbohydrate diet also appears to result in preferential loss of abdominal fat mass. ${ }^{58}$ It is well established that diet improves IR in patients with PCOS, ${ }^{59-61}$ while exercise also appears to improve IR and to reduce visceral fat in this population. ${ }^{62,63}$ Lifestyle changes reduced the risk of progression from IGT to T2DM in the general population ${ }^{64,65}$ and in patients with PCOS. ${ }^{66}$

Additionally, the Androgen Excess and PCOS Society as well as the Endocrine Society suggest the use of metformin in patients with PCOS who have no improvement in IGT despite lifestyle changes and in normal weight patients with IGT. ${ }^{56,57}$ Several studies showed that treatment with metformin improves IR and induces weight loss in patients with PCOS and that it might also induce reversion from IGT to normal glucose tolerance and prevent the development of IGT or T2DM. ${ }^{67-70}$ However, it should be noted that in the Diabetes Prevention Program study ( $n=3,234$ patients with IFG or IGT), metformin was less effective than lifestyle changes in reducing the incidence of T2DM (31 and 58\% reduction, respectively). ${ }^{62}$ Importantly, the use of antiobesity agents is not recommended because of limited data on their safety and efficacy in patients with PCOS..$^{57,61,71}$

In patients with PCOS who are diagnosed with T2DM there are no specific recommendations for the choice of antidiabetic treatment. ${ }^{72}$ Accordingly, metformin and lifestyle changes are the treatment of choice, while any antidiabetic agent can be added in patients who do not achieve glycemic targets despite treatment with metformin (i.e. sulfonylureas, pioglitazone, dipeptidyl peptidase 4 inhibitors, glucagonlike peptide- 1 receptor agonists, sodium-glucose cotransporter 2 inhibitors or basal insulin). ${ }^{72}$ Among the available options, pioglitazone appears to improve insulin sensitivity to a similar degree as metformin, both agents exerting a synergistic effect on IR in patients with PCOS. ${ }^{73,77}$ However, safety concerns, including the risk of weight gain and edema, limit the use of pioglitazone in this population. ${ }^{54} \mathrm{Lim}-$ ited data also suggest that glucagon-like peptide 1 analogues combined with metformin attenuate IR and reduce weight more effectively than metformin monotherapy. ${ }^{75,76}$ However, only insulin, metformin and glyburide can be safely used in pregnancy and therefore appropriate contraceptive measures should be implemented in patients receiving other antidiabetic agents. ${ }^{77}$

\section{CONCLUSIONS}

Both prediabetes and T2DM are highly prevalent in patients with PCOS. Accordingly, regular screening is recommended in this population for the early identification of impaired glucose metabolism, particularly in overweight or obese patients and in those with a family history of T2DM. Prevention of T2DM in patients with IGT is primarily based on lifestyle 
changes, whereas metformin might be considered in selected cases. Both diet and exercise have multiple beneficial effects on glucose metabolism in this population. The treatment of T2DM is similar in patients with and without PCOS but appropriate contraceptive measures should be implemented in patients receiving treatments other than insulin, metformin or glyburide.

\section{REFERENCES}

1. Knochenhauer ES, Key TJ, Kahsar-Miller M, Waggoner W, Boots LR, Azziz R, 1998 Prevalence of the polycystic ovary syndrome in unselected black and white women of the southeastern United States: a prospective study. J Clin Endocrinol Metab 83: 3078-3082.

2. Diamanti-Kandarakis E, Kouli CR, Bergiele AT, et al, 1999 A survey of the polycystic ovary syndrome in the Greek island of Lesbos: hormonal and metabolic profile. J Clin Endocrinol Metab 84: 4006-4011.

3. Rotterdam ESHRE/ASRM-Sponsored PCOS Consensus Workshop Group, 2004. Revised 2003 consensus on diagnostic criteria and long-term health risks related to polycystic ovary syndrome. Fertil Steril 81: 19-25.

4. Azziz R, Carmina E, Dewailly D, et al, 2009 Task Force on the Phenotype of the Polycystic Ovary Syndrome of The Androgen Excess and PCOS Society: the Androgen Excess and PCOS Society criteria for the polycystic ovary syndrome: the complete task force report. Fertil Steril 91: 456-488.

5. Moran LJ, Misso ML, Wild RA, Norman RJ, 2010 Impaired glucose tolerance, type 2 diabetes and metabolic syndrome in polycystic ovary syndrome: a systematic review and meta-analysis. Hum Reprod Update 16: 347-363.

6. Legro RS, Kunselman AR, Dodson WC, Dunaif A, 1999 Prevalence and predictors of risk for type 2 diabetes mellitus and impaired glucose tolerance in polycystic ovary syndrome: a prospective, controlled study in 254 affected women. J Clin Endocrinol Metab 84: 165-169.

7. Lo JC, Feigenbaum SL, Yang J, Pressman AR, Selby JV, Go AS, 2006 Epidemiology and adverse cardiovascular risk profile of diagnosed polycystic ovary syndrome. $\mathrm{J}$ Clin Endocrinol Metab 91: 1357-1363.

8. Talbott EO, Zborowski JV, Rager JR, Kip KE, Xu X, Orchard TJ, 2007 Polycystic ovarian syndrome (PCOS): a significant contributor to the overall burden of type 2 diabetes in women. J Womens Health (Larchmt) 16: 191-197.

9. Ford ES, Li C, Sattar N, 2008 Metabolic syndrome and incident diabetes: current state of the evidence. Diabetes Care 31: 1898-1904.

10. Cussons AJ, Watts GF, Burke V, Shaw JE, Zimmet PZ, Stuckey BG, 2008 Cardiometabolic risk in polycystic ovary syndrome: a comparison of different approaches to defining the metabolic syndrome. Hum Reprod 23:
2352-2358.

11. Panidis D, Macut D, Tziomalos K, et al, 2013 Prevalence of metabolic syndrome in women with polycystic ovary syndrome. Clin Endocrinol (Oxf) 78: 586-592.

12. Lerchbaum E, Schwetz V, Giuliani A, Obermayer-Pietsch B, 2013 Assessment of glucose metabolism in polycystic ovary syndrome: $\mathrm{HbA}_{\mathrm{cc}}$ or fasting glucose compared with the oral glucose tolerance test as a screening method. Hum Reprod 28: 2537-2544.

13. Celik C, Abali R, Bastu E, Tasdemir N, Tasdemir UG, Gul A, 2013 Assessment of impaired glucose tolerance prevalence with hemoglobin $\mathrm{A}_{1 \mathrm{c}}$ and oral glucose tolerance test in 252 Turkish women with polycystic ovary syndrome: a prospective, controlled study. Hum Reprod 28: 1062-1068.

14. Norman RJ, Masters L, Milner CR, Wang JX, Davies MJ, 2001 Relative risk of conversion from normoglycaemia to impaired glucose tolerance or non-insulin dependent diabetes mellitus in polycystic ovarian syndrome. Hum Reprod 16: 1995-1998.

15. Boudreaux MY, Talbott EO, Kip KE, Brooks MM, Witchel SF, 2006 Risk of T2DM and impaired fasting glucose among PCOS subjects: results of an 8-year follow-up. Curr Diab Rep 6: 77-83.

16. Legro RS, Gnatuk CL, Kunselman AR, Dunaif A, 2005 Changes in glucose tolerance over time in women with polycystic ovary syndrome: a controlled study. J Clin Endocrinol Metab 90: 3236-3242.

17. Gambineri A, Patton L, Altieri P, et al, 2012 Polycystic ovary syndrome is a risk factor for type 2 diabetes: results from a long-term prospective study. Diabetes 61: 2369-2374.

18. Morgan CL, Jenkins-Jones S, Currie CJ, Rees DA, 2012 Evaluation of adverse outcome in young women with polycystic ovary syndrome versus matched, reference controls: a retrospective, observational study. J Clin Endocrinol Metab 97: 3251-3260.

19. Carmina E, Lobo RA, 2004 Use of fasting blood to assess the prevalence of insulin resistance in women with polycystic ovary syndrome. Fertil Steril 82: 661-665.

20. DeUgarte CM, Bartolucci AA, Azziz R, 2005 Prevalence of insulin resistance in the polycystic ovary syndrome using the homeostasis model assessment. Fertil Steril 83: 1454-1460.

21. Macut D, Micic D, Parapid B, et al, 2002 Age and body mass related changes of cardiovascular risk factors in women with polycystic ovary syndrome. Vojnosanit Pregl 59: 593-599.

22. Panidis D, Tziomalos K, Macut D, et al, 2012 Crosssectional analysis of the effects of age on the hormonal, metabolic, and ultrasonographic features and the prevalence of the different phenotypes of polycystic ovary syndrome. Fertil Steril 97: 494-500.

23. Dunaif A, Segal KR, Futterweit W, Dobrjansky A, 1989 Profound peripheral insulin resistance, independent of obesity, in polycystic ovary syndrome. Diabetes 38: 
1165-1174.

24. Macut D, Bjekić-Macut J, Rahelić D, Doknić M, 2017 Insulin and the polycystic ovary syndrome. Diabetes Res Clin Pract 130: 163-170.

25. Stepto NK, Cassar S, Joham AE, et al, 2013 Women with polycystic ovary syndrome have intrinsic insulin resistance on euglycaemic-hyperinsulaemic clamp. Hum Reprod 28: 777-784.

26. Cassar S, Misso ML, Hopkins WG, Shaw CS, Teede HJ, Stepto NK, 2016 Insulin resistance in polycystic ovary syndrome: a systematic review and meta-analysis of euglycaemic-hyperinsulinaemic clamp studies. Hum Reprod 31: 2619-2631.

27. O’Meara NM, Blackman JD, Ehrmann DA, et al, 1993 Defects in beta-cell function in functional ovarian hyperandrogenism. J Clin Endocrinol Metab 76: 1241-1247.

28. Ciampelli M, Fulghesu AM, Cucinelli F, et al, 1997 Heterogeneity in beta cell activity, hepatic insulin clearance and peripheral insulin sensitivity in women with polycystic ovary syndrome. Hum Reprod 12: 1897-1901.

29. Vrbíková J, Bendlová B, Hill M, Vanková M, Vondra K, Stárka L, 2002 Insulin sensitivity and beta-cell function in women with polycystic ovary syndrome. Diabetes Care 25: 1217-1222.

30. Yildiz BO, Knochenhauer ES, Azziz R, 2008 Impact of obesity on the risk for polycystic ovary syndrome. J Clin Endocrinol Metab 93: 162-168.

31. Carmina E, Bucchieri S, Esposito A, et al, 2007 Abdominal fat quantity and distribution in women with polycystic ovary syndrome and extent of its relation to insulin resistance. J Clin Endocrinol Metab 92: 2500-2505.

32. Ehrmann DA, Barnes RB, Rosenfield RL, Cavaghan MK, Imperial J, 1999 Prevalence of impaired glucose tolerance and diabetes in women with polycystic ovary syndrome. Diabetes Care 22: 141-146.

33. Espinós-Gómez JJ, Corcoy R, Calaf J, 2009 Prevalence and predictors of abnormal glucose metabolism in Mediterranean women with polycystic ovary syndrome. Gynecol Endocrinol 25:199-204.

34. Boumosleh JM, Grundy SM, Phan J, Neeland IJ, Chang A, Vega GL, 2017 Metabolic Concomitants of Obese and Nonobese Women With Features of Polycystic Ovarian Syndrome. J Endocr Soc 1: 1417-1427.

35. Scott D, Joham A, Teede H, et al, 2016 Associations of Vitamin D with Inter- and Intra-Muscular Adipose Tissue and Insulin Resistance in Women with and without Polycystic Ovary Syndrome. Nutrients 2016: 8.pii:E774.

36. Welt CK, Gudmundsson JA, Arason G, et al, 2006 Characterizing discrete subsets of polycystic ovary syndrome as defined by the Rotterdam criteria: the impact of weight on phenotype and metabolic features. J Clin Endocrinol Metab 91: 4842-4848.

37. Goverde AJ, van Koert AJ, Eijkemans MJ, et al, 2009 Indicators for metabolic disturbances in anovulatory women with polycystic ovary syndrome diagnosed according to the Rotterdam consensus criteria. Hum
Reprod 24: 710-717.

38. Panidis D, Tziomalos K, Misichronis G, et al, 2012 Insulin resistance and endocrine characteristics of the different phenotypes of polycystic ovary syndrome: a prospective study. Hum Reprod 27: 541-549.

39. Corbould A, 2007 Chronic testosterone treatment induces selective insulin resistance in subcutaneous adipocytes of women. J Endocrinol 192: 585-594.

40. Polderman KH, Gooren LJ, Asscheman H, Bakker A, Heine RJ, 1994 Induction of insulin resistance by androgens and estrogens. J Clin Endocrinol Metab 79: 265-271.

41. Dahlgren E, Landin K, Krotkiewski M, Holm G, Janson PO, 1998 Effects of two antiandrogen treatments on hirsutism and insulin sensitivity in women with polycystic ovary syndrome. Hum Reprod 13: 2706-2711.

42. Gambineri A, Pelusi C, Genghini S, et al, 2004 Effect of flutamide and metformin administered alone or in combination in dieting obese women with polycystic ovary syndrome. Clin Endocrinol (Oxf) 60: 241-249.

43. Gambineri A, Patton L, Vaccina A, et al, 2006 Treatment with flutamide, metformin, and their combination added to a hypocaloric diet in overweight-obese women with polycystic ovary syndrome: a randomized, 12-month, placebo-controlled study. J Clin Endocrinol Metab 91: 3970-3980.

44. Lerchbaum E, Schwetz V, Giuliani A, Obermayer-Pietsch B, 2014 Influence of a positive family history of both type 2 diabetes and PCOS on metabolic and endocrine parameters in a large cohort of PCOS women. Eur J Endocrinol 170: 727-739.

45. Vink JM, Sadrzadeh S, Lambalk CB, Boomsma DI, 2006 Heritability of polycystic ovary syndrome in a Dutch twin-family study. J Clin Endocrinol Metab 91: 2100-2104.

46. Goodarzi MO, Jones MR, Li X, et al, 2012 Replication of association of DENND1A and THADA variants with polycystic ovary syndrome in European cohorts. J Med Genet 49: 90-95.

47. Mutharasan P, Galdones E, Peñalver Bernabé B, et al, 2013 Evidence for chromosome 2p16.3 polycystic ovary syndrome susceptibility locus in affected women of European ancestry. J Clin Endocrinol Metab 98: E185-90.

48. Welt CK, Styrkarsdottir U, Ehrmann DA, et al, 2012 Variants in DENND1A are associated with polycystic ovary syndrome in women of European ancestry. J Clin Endocrinol Metab 97: E1342-1347.

49. de Melo AS, Dias SV, Cavalli Rde C, et al, 2015 Pathogenesis of polycystic ovary syndrome: multifactorial assessment from the foetal stage to menopause. Reproduction 150: R11-24.

50. Stefanaki C, Peppa M, Mastorakos G, Chrousos GP, 2017 Examining the gut bacteriome, virome, and mycobiome in glucose metabolism disorders: Are we on the right track? Metabolism 73: 52-66.

51. Lindheim L, Bashir M, Münzker J, et al, 2017 Alterations 
in Gut Microbiome Composition and Barrier Function Are Associated with Reproductive and Metabolic Defects in Women with Polycystic Ovary Syndrome (PCOS): A Pilot Study. PLoS One 2017;12:e0168390.

52. Cree-Green M, Rahat H, Newcomer BR, et al, 2017 Insulin Resistance, Hyperinsulinemia, and Mitochondria Dysfunction in Nonobese Girls With Polycystic Ovarian Syndrome. J Endocr Soc 1: 931-944.

53. Goodman NF, Cobin RH, Futterweit W, Glueck JS, Legro RS, Carmina E; American Association of Clinical Endocrinologists (AACE); 2015 American College of Endocrinology (ACE); Androgen Excess and PCOS Society. American Association of Clinical Endocrinologists, American College of Endocrinology, and Androgen Excess and PCOS Society disease state clinical review: guide to the best practices in the evaluation and treatment of polycystic ovary syndrome - part 2. Endocr Pract 21: 1415-1426.

54. Conway G, Dewailly D, Diamanti-Kandarakis E, et al, 2014 ESE PCOS Special Interest Group. The polycystic ovary syndrome: a position statement from the European Society of Endocrinology. Eur J Endocrinol 171: P1-29.

55. Hurd WW, Abdel-Rahman MY, Ismail SA, Abdellah MA, Schmotzer CL, Sood A, 2011 Comparison of diabetes mellitus and insulin resistance screening methods for women with polycystic ovary syndrome. Fertil Steril 96: 1043-1047.

56. Legro RS, Arslanian SA, Ehrmann DA, et al, Endocrine Society, 2013 Diagnosis and treatment of polycystic ovary syndrome: an Endocrine Society clinical practice guideline. J Clin Endocrinol Metab 98: 4565-4592.

57. Wild RA, Carmina E, Diamanti-Kandarakis E, et al, 2010 Assessment of cardiovascular risk and prevention of cardiovascular disease in women with the polycystic ovary syndrome: a consensus statement by the Androgen Excess and Polycystic Ovary Syndrome (AE-PCOS) Society. J Clin Endocrinol Metab 95: 2038-2049.

58. Goss AM, Chandler-Laney PC, Ovalle F, et al, 2014 Effects of a eucaloric reduced-carbohydrate diet on body composition and fat distribution in women with PCOS. Metabolism 63: 1257-1264.

59. Thomson RL, Buckley JD, Noakes M, Clifton PM, Norman RJ, Brinkworth GD, 2008 The effect of a hypocaloric diet with and without exercise training on body composition, cardiometabolic risk profile, and reproductive function in overweight and obese women with polycystic ovary syndrome. J Clin Endocrinol Metab 93: 3373-3380.

60. Palomba S, Falbo A, Giallauria F, et al, 2010 Six weeks of structured exercise training and hypocaloric diet increases the probability of ovulation after clomiphene citrate in overweight and obese patients with polycystic ovary syndrome: a randomized controlled trial. Hum Reprod 25: 2783-2791.

61. Panidis D, Tziomalos K, Papadakis E, et al, 2014 The role of orlistat combined with lifestyle changes in the management of overweight and obese patients with polycystic ovary syndrome. Clin Endocrinol (Oxf) 80: 432-438.

62. Vigorito C, Giallauria F, Palomba S, et al, 2007 Beneficial effects of a three-month structured exercise training program on cardiopulmonary functional capacity in young women with polycystic ovary syndrome. J Clin Endocrinol Metab 92: 1379-1384.

63. Hutchison SK, Stepto NK, Harrison CL, Moran LJ, Strauss BJ, Teede HJ, 2011 Effects of exercise on insulin resistance and body composition in overweight and obese women with and without polycystic ovary syndrome. J Clin Endocrinol Metab 96: E48-56.

64. Tuomilehto J, Lindström J, Eriksson JG, et al, 2001 Finnish Diabetes Prevention Study Group. Prevention of type 2 diabetes mellitus by changes in lifestyle among subjects with impaired glucose tolerance. N Engl J Med 344: 1343-1350.

65. Knowler WC, Barrett-Connor E, Fowler SE, et al, 2002 Diabetes Prevention Program Research Group. Reduction in the incidence of type 2 diabetes with lifestyle intervention or metformin. N Engl J Med 346: 393-403.

66. Domecq JP, Prutsky G, Mullan RJ, et al, 2013 Lifestyle modification programs in polycystic ovary syndrome: systematic review and meta-analysis. J Clin Endocrinol Metab 98: 4655-4663.

67. Koiou E, Tziomalos K, Katsikis I, Delkos D, Tsourdi EA, Panidis D, 2013 Disparate effects of pharmacotherapy on plasma plasminogen activator inhibitor-1 levels in women with the polycystic ovary syndrome. Hormones (Athens) 12: 559-566.

68. Trolle B, Flyvbjerg A, Kesmodel U, Lauszus FF, 2007 Efficacy of metformin in obese and non-obese women with polycystic ovary syndrome: a randomized, doubleblinded, placebo-controlled cross-over trial. Hum Reprod 22: 2967-2973.

69. Moghetti P, Castello R, Negri C, et al, 2000 Metformin effects on clinical features, endocrine and metabolic profiles, and insulin sensitivity in polycystic ovary syndrome: a randomized, double-blind, placebo controlled 6-month trial, followed by open, long-term clinical evaluation. J Clin Endocrinol Metab 85: 139-146.

70. Nieuwenhuis-Ruifrok AE, Kuchenbecker WK, Hoek A, Middleton P, Norman RJ, 2009 Insulin sensitizing drugs for weight loss in women of reproductive age who are overweight or obese: systematic review and meta-analysis. Hum Reprod Update 15: 57-68.

71. Jayagopal V, Kilpatrick ES, Holding S, Jennings PE, Atkin SL, 2005 Orlistat is as beneficial as metformin in the treatment of polycystic ovarian syndrome. J Clin Endocrinol Metab 90: 729-733.

72. American Diabetes Association, 2017 8. Pharmacologic Approaches to Glycemic Treatment. Diabetes Care 40: Suppl 1: 64-74.

73. Li XJ, Yu YX, Liu CQ, et al, 2011 Metformin vs thiazolidinediones for treatment of clinical, hormonal and 
metabolic characteristics of polycystic ovary syndrome: a meta-analysis. Clin Endocrinol (Oxf) 74: 332-339.

74. Glueck CJ, Moreira A, Goldenberg N, Sieve L, Wang P, 2003 Pioglitazone and metformin in obese women with polycystic ovary syndrome not optimally responsive to metformin. Hum Reprod 18: 1618-1625.

75. Elkind-Hirsch K, Marrioneaux O, Bhushan M, Vernor D, Bhushan R, 2008 Comparison of single and combined treatment with exenatide and metformin on menstrual cyclicity in overweight women with polycystic ovary syndrome. J Clin Endocrinol Metab 93: 2670-2678.

76. Jensterle Sever M, Kocjan T, Pfeifer M, Kravos NA, Janez A, 2014 Short-term combined treatment with liraglutide and metformin leads to significant weight loss in obese women with polycystic ovary syndrome and previous poor response to metformin. Eur J Endocrinol 170: 451-459.

77. American Diabetes Association, 2017 13. Management of diabetes in pregnancy. Diabetes Care 40: Suppl 1: 114-119. 